INNOVATION AND IMPROVEMENT

\title{
IMMII Implementation Science Workshop: Barriers and Facilitators to Increasing Mammography Screening Rates in California's Public Hospitals
}

\author{
Cassidy Clarity, BA ${ }^{1,2}$, Gato Gourley, MSc ${ }^{1,2}$, Courtney Lyles, Phd ${ }^{1,2}$, Sara Ackerman, PhD, $M P H^{3}$, \\ Margaret A. Handley, $\mathrm{PhD}, \mathrm{MPH}^{2,4}$, Dean Schillinger, $\mathrm{MD}^{1,2}$, Urmimala Sarkar, $\mathrm{MD}, \mathrm{MPH}{ }^{1,2}$, and \\ Joseph Conigliaro, MD, MPH, FACP 5
}

\begin{abstract}
${ }^{1}$ Center for Vulnerable Populations, University of California San Francisco, San Francisco, CA, USA; '2Division of General Internal Medicine, School of Medicine, University of California San Francisco, San Francisco, CA, USA; ${ }^{3}$ Department of Social Behavioral Sciences, School of Nursing, University of California San Francisco, San Francisco, CA, USA; ${ }^{4}$ Department of Epidemiology and Biostatistics, School of Medicine, University of California San Francisco, San Francisco, CA, USA; ${ }^{5}$ Division of General Internal Medicine, Hofstra Northwell School of Medicine, Hempstead, NY, USA.
\end{abstract}

J Gen Intern Med 32(6):697-705

DOI: $10.1007 / \mathrm{s} 11606-016-3929-2$

(c) Society of General Internal Medicine 2017

\section{CASE}

\section{INTRODUCTION}

The California Delivery System Reform Incentive Payment (DSRIP) program is a pay-for-performance Medicaid waiver initiative that supports public healthcare systems in delivering high-quality care, requires performance measurement and reporting, and is administered through the California Association of Public Hospitals (CAPH). ${ }^{1}$ In March 2013, participating health systems went beyond a reporting-only metric and voluntarily engaged in performance improvement activities in efforts to reach a mammography screening rate of $76.6 \%$ of all eligible women. California's public hospital systems undertook this initiative in the context of population challenges; women of lower socioeconomic status and uninsured women are less likely than their wealthier, insured counterparts to receive a mammogram. ${ }^{2}$ Enhancing mammography screening is particularly important in the safety net, because low-income, uninsured and Medicaid patients are more often diagnosed with breast cancer at later stages, ${ }^{3-8}$ and have higher costs of care ${ }^{9}$ and lower survival rates ${ }^{8,10-13}$ than wealthier, insured women. Preventive screening has been shown to mitigate the negative effects of low income on stage of breast cancer at diagnosis. ${ }^{7}$

Together with the University of California San Francisco (UCSF) Center for Vulnerable Populations (CVP), CAPH and

Dr. Sarkar is the senior author of the case section of the manuscript.

Dr. Conigliaro is the author of the commentary section of the manuscript.

Editors' note: In this installment of Implementation Science Workshop, Ms. Clarity and colleagues describe the facilitators and barriers of a statewide initiative to increase mammogram screening rates in California's public hospitals. In the accompanying commentary, Joseph Conigliaro, MD, MPH, explains the importance of using theoretical frameworks in implementation research.

Published online February 10, 2017 its member health systems worked to reach this goal as a part of the collaborative Public Healthcare system Evidence Network and Innovation eXchange (PHoENIX), ${ }^{14}$ which facilitates information sharing among DSRIP participants. This study used methods from implementation science, defined as "the study of methods to promote the integration of research findings and evidence into healthcare policy and practice." 15 Specifically, we chose the Consolidated Framework for Implementation Research (CFIR) to evaluate barriers and facilitators to increasing mammography rates in the target population, because it allows for comprehensive assessment of implementation in the healthcare setting. ${ }^{16}$

\section{SETTING AND PARTICIPANTS}

Below we describe the setting, participants, and performance target of this implementation effort. We then discuss the CFIR framework and analysis methods in the "Program Evaluation" section. Lastly, we present the results in the context of the CFIR domains, in addition to our specific contextual factors, in the "Results and Challenges" and "Future Plans" sections.

Members from both UCSF and the Safety Net Institute (SNI) conducted 16 qualitative interviews with 23 key informants for mammography representing 20 of California's 21 public hospital systems. Each hospital system's SNI representative identified mammography key informants who possessed the greatest overall understanding of screening efforts and represented several mid-level career categories (Appendix 1). A semi-structured interview guide was used to discuss barriers and facilitators to reaching the new mammography metric (Appendix 2). Some separate hospital systems filed consolidated DSRIP plans, resulting in 17 total plans. We were unable to conduct an interview with one of these plan participants, resulting in 16 total interviews. The interviews were conducted between October and November of 2013, lasted 30-45 min, and were audio-recorded and professionally transcribed to facilitate analysis. Approval from the UCSF Committee on Human Research was obtained to conduct this study. 


\section{Performance Target}

The health systems sought to reach a $76.6 \%$ rate of mammography screening within the prior 24 months for women aged 50-74 years. The metric was based on the 90th percentile benchmark for Healthcare Effectiveness Data and Information Set (HEDIS) Medicare Preferred Provider Organizations, as developed by the National Committee for Quality Assurance. ${ }^{17}$

\section{PROGRAM EVALUATION}

\section{Framework}

We analyzed our data using the Consolidated Framework for Implementation Research. We chose CFIR because it provides an explanatory model for how innovations are implemented in healthcare systems. It consists of five overarching domains, with 39 more specifically defined constructs within these five domains, and was developed from roughly 20 theories in implementation science. ${ }^{16-18}$ For this study, barriers and facilitators shaping participating sites' mammography screening activities were interpreted using the five overarching CFIR domains: Intervention characteristics comprise factors such as the adaptability of the intervention, the perceived relative advantage, and the complexity and cost of the intervention. The characteristics of individuals domain covers personal attributes of individuals within the organization as they pertain to the implementation of the intervention. The outer setting domain encompasses the needs and resources of the people served by the organization and the interactions between the organization and external organizations and policies. The inner setting domain is defined by the organization's culture, structural characteristics, and readiness for implementation. Lastly, the process domain includes planning, executing, and evaluating the implementation. ${ }^{16}$ While CFIR's five domains described our data well, the 39 constructs were not sufficient to encapsulate our data. Therefore, through inductive coding and identification of emergent themes, we developed our own study-specific themes that better encompassed the comments of our interviewees than CFIR's 39 constructs. We call our themes "contextual factors," defined as the elements that "promote the successful implementation of evidence into practice,"19 and use these contextual factors within the five larger CFIR domains in place of CFIR's 39 constructs.

\section{Coding Process}

We used conventional content analysis ${ }^{20}$ to inductively identify unifying topics across all interviews. A single investigator (CC) read all interviews and developed preliminary codes, which were then discussed with the investigative team (US, GG) using a consensus method. ${ }^{21}$ Final codes were applied to all interview transcripts. Fourteen study-specific contextual factors were determined that best described the coded content, and were categorized into each of the five CFIR domains. Nine contextual factors within three domains were more frequently discussed and therefore highlighted for further analysis. We do not use the intervention characteristics domain, because the interventions were not standardized among the sites, and characterizing this domain proved to be infeasible. We do not report characteristics of individuals, because themes in this domain did not emerge from the interviews. The CFIR domains and contextual factors are shown in Figure 1. Table 1 shows the perceptions of contextual factors by number of interviews, and Table 2 shows representative quotes by contextual factor.

\section{RESULTS}

\section{Process Domain}

Because there are several well-known evidence-based interventions for increasing mammography rates, ${ }^{22-26}$ practices were common across sites and included outreach to patients by letters and calls, in-reach by scheduling mammography during an unrelated appointment, same-day mammography screening, standing orders, and data tracking processes. The contextual factors in this domain discussed most often were outreach letters and calls, which were perceived by interviewees as facilitating an increase in mammography screening rates.

\section{Inner Setting Domain}

The majority of interview excerpts, however, pertained to the inner setting domain, and focused on larger systemic factors affecting the success of the interventions outlined above. The contextual factors identified in this domain include the electronic health record (EHR), mammography registries, reporting methods, interoperable technology systems, and the patientcentered medical home (PCMH) model.

EHRs. About half of the interviewees perceived their EHRs as barriers and half as facilitators to increasing mammography screening rates. Interviewees who perceived their EHR as a facilitator had established EHRs that supported in-reach, outreach, and data tracking. Interviewees with the most positive perceptions of overall health information technology (IT) reported having EHRs with multiple functionalities (e.g., had registry and reporting capabilities built in, and were being used for mammography).

The EHRs described as barriers were often newly or incompletely implemented and lacked interoperability. Interviewees noted that learning how to use the EHR consumed excessive time and attention. For example: "The challenge is that we have this brand new EMR that's gone live and so people are still trying to... understand its current capacity just as it relates to ambulatory care visits and surviving and keeping our heads above water."

Mammography Registries. Interviewees perceived screening registries as positively affecting mammography screening efforts. Of the 16 interviews, only three mentioned existing 


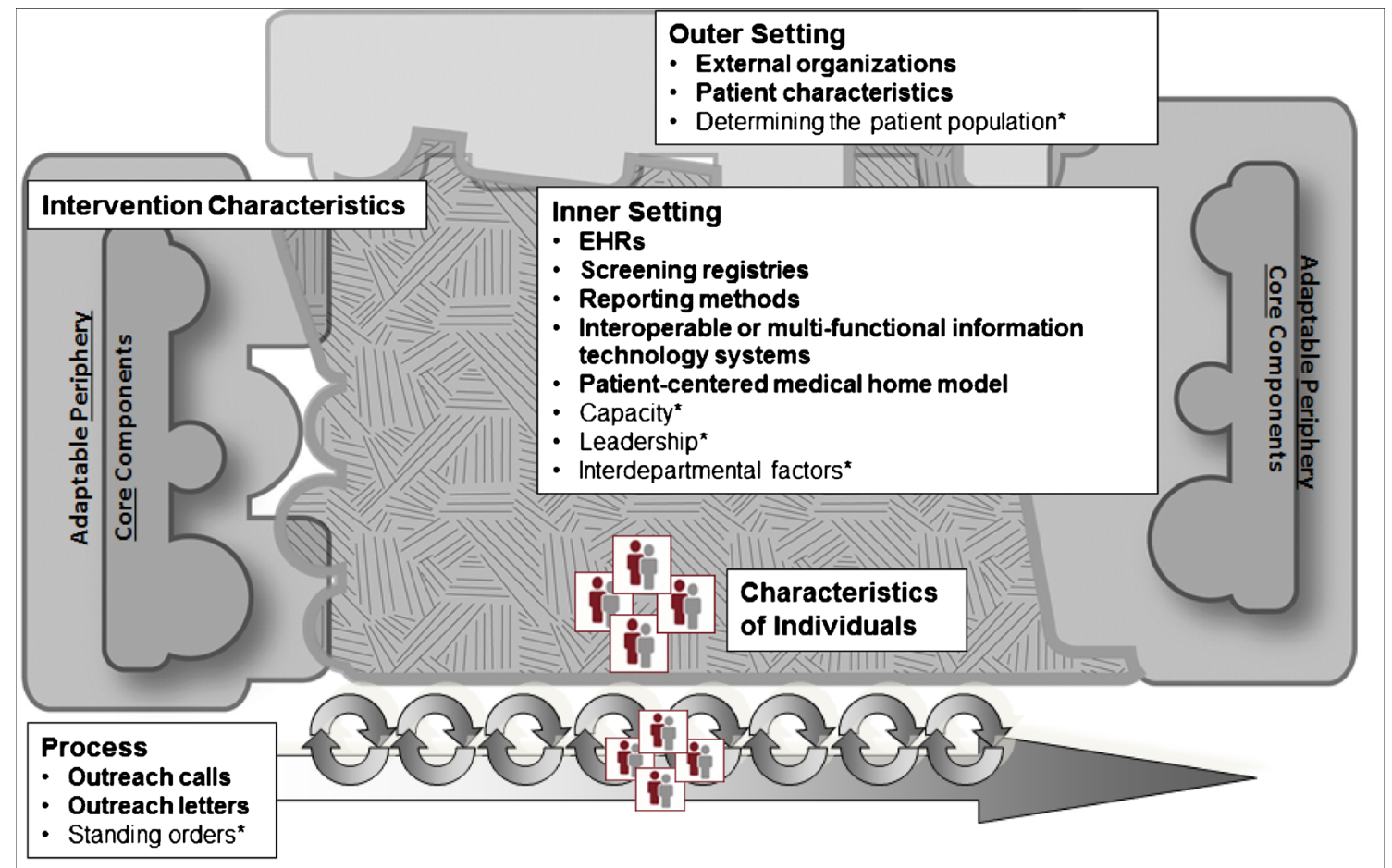

* Contextual factors not sufficiently discussed to warrant further analysis; 9 final contextual factors in bold

Adapted from Damschroeder and Hagedorn, 2011

Figure 1 Overlapping domains of the Consolidated Framework for Implementation Research with associated study-specific contextual factors.

registries as a barrier. The registries at these sites either had inaccurate data or required extra manual effort to render the registry functional. All other participant interviews either discussed registries as a facilitator $(n=11)$ or discussed lacking a registry as a barrier $(n=2)$.

Reporting Methods. Having data on mammography screening rates available to providers was perceived as a facilitator to reaching the DSRIP goal, whereas a lack of reporting capabilities was perceived as a barrier. Interviewees with positive perceptions of reporting methods engaged in monthly or quarterly reporting, produced site- or provider-specific reports, and had forums available to discuss best practices.

Interoperable Technology. Most interviewees mentioned interoperability of technology as a barrier. Many of the
EHRs, both recently adopted and well-established, lacked interoperability with other technology systems such as registries, patient portals, and external electronic systems, making tracking and reporting difficult.

The Patient-Centered Medical Home Model. In 12 interviews, interviewees reported using aspects of the $\mathrm{PCMH}$ model and perceived it as helping to increase mammography rates. The Agency for Healthcare Research and Quality defines the $\mathrm{PCMH}$ as providing comprehensive care, a patientcentered approach, team-based care, accessible services, and a focus on quality and safety. ${ }^{27}$ Interviewees noted opportunity for patient engagement, better follow-up, and shared responsibility as reasons that the PCMH model contributed to increased rates. For example: "Today, all of our primary care clinics do inreach and outreach and have teamlet models...so

Table 1 Perceptions of Contextual Factors by DSRIP Plan Participants $(n=16)$

\begin{tabular}{|c|c|c|c|c|c|}
\hline $\begin{array}{l}\text { CFIR } \\
\text { domain }\end{array}$ & Contextual factor & $\begin{array}{l}\text { Perceived } \\
\text { facilitator }(n)\end{array}$ & $\begin{array}{l}\text { Perceived } \\
\text { barrier }(n)\end{array}$ & $\begin{array}{l}\text { Neutral/not } \\
\text { discussed }(n)\end{array}$ & $\begin{array}{l}\text { Lack of factor perceived } \\
\text { as barrier }(n)\end{array}$ \\
\hline \multirow[t]{2}{*}{ Process } & Outreach letters to patients & 13 & 0 & 3 & 0 \\
\hline & Outreach calls to patients & 10 & 0 & 6 & 0 \\
\hline \multirow{5}{*}{$\begin{array}{l}\text { The inner } \\
\text { setting }\end{array}$} & Electronic health record & 6 & 7 & 3 & 0 \\
\hline & Mammography registry & 11 & 3 & 0 & 2 \\
\hline & Reporting method & 9 & 1 & 4 & 2 \\
\hline & $\begin{array}{l}\text { Interoperable or multi-functional } \\
\text { technology systems }\end{array}$ & 4 & 0 & 6 & 6 \\
\hline & $\begin{array}{l}\text { Patient-centered medical home } \\
\text { model }\end{array}$ & 12 & 0 & 3 & 1 \\
\hline \multirow{2}{*}{$\begin{array}{l}\text { The outer } \\
\text { setting }\end{array}$} & Patient characteristics & 0 & 13 & 3 & 0 \\
\hline & External organizations & 9 & 2 & 5 & 0 \\
\hline
\end{tabular}


Table 2 Perceived Facilitators and Barriers to Meeting the 2013 DSRIP Mammography Screening Measure in the California Safety Net

\begin{tabular}{lll}
\hline \hline Contextual factor & Barrier/ & Example quote(s) \\
& Facilitator & \\
\hline
\end{tabular}

Process

Outreach letters and calls

Facilitator

Facilitator

Inner setting

Electronic health record

Facilitator

Barrier

Mammography registry

Facilitator

Reporting methods

Barrier

Facilitator

Barrier

Interoperable information technology systems

Facilitator

Patient-centered medical home model

Facilitator

Outer setting

Patient characteristics

Barrier

Barrier

External organizations

Barrier

Barrier
"We are contracting with a company called [retracted] who does outgoing phone calls to patients for care gaps, and after the patient is able to identify themselves on the phone, it will ask them about whether or not they've had mammography."

"The radiology department also sends out letters when it's a year. So if they've had a mammogram within our system in radiology, they send out a letter. So a lot of the times the patients themselves will come present to the clinic, saying, 'Oh, I got the letter from radiology. It's time for me to do my mammogram."”

"It's really the tools that the electronic health record has provided us, just to make it pretty obvious and pretty easy, yes. It really has everything to do with the EHR and-well, not everything. It's half. The other half is... all of our primary care clinics do in-reach and outreach and have teammate models."

"We also did something else that the literature says not to do: that was implement an EHR at the same time that we were implementing these models of care...I think what happened was implementing the EHR has sucked the creativity out of most of the workers at the family health centers. I think they have change fatigue trying to do that and look at these other issues."

"The ability to use the disease registry to its fullest capacity has been a real bonus, because you have to realize we don't really even have a true electronic health record yet."

"Right now there's no registry, and we are reliant on a system that isn't outpatient-based."

"We have a dashboard where the data shows up every month. Every month we look at the denominator and the numerator, and the number shows up on the dashboard. The dashboard is available to everyone in the counties and on the internet site. Then you can go and click on the measure, and they can see the running chart for the past 18 months."

"Now it's just been very difficult because we have information in a bunch of different systems. But at this point we are not sharing it with the individual providers or clinics, although the goal certainly is to do that, but we're not doing it yet."

"The opportunity to engage our EMR team with the work of DSRIP on the category three measures has helped us develop better reporting, building in exclusions, inclusions, and then coming up with a percentage has helped us make that an element in a basic quality report that physicians will start receiving as of today."

"So the part that we're trying to work now-as you can see we have three separate systems. We have [software] that has the demographics, our radiology system that will tell us if they had a mammogram or not, and then our [EHR] that will tell us if we did ever order a mammogram, and maybe they never had it done, which is another important piece of information that we would like to have."

"Well, one thing that we have done is we've implemented a medical home model. We have care coordinators in the offices and...we've told them explicitly, 'When you interact with a patient, take that opportunity to look for quality care gaps."”

"The patient's fear of cost is a significant challenge."

"I think different cultures have a different sense of how important preventive screening is. If we could figure out a way to message that better that speaks very specifically to those beliefs in that particular culture, that would also be helpful."

"Where it becomes a challenge is with our Medi-Cal patients and/or our other patients, who through agreement are going to a community hospital, that there is no electronic interface so we have to take whatever reports we get and then scan them into the system. So it is something of a dissatisfier for us."

"I'd say the one other thing - that just reminds me, another barrier is that because most of our women get their mammograms through an [external program], the [external program] requires a clinical breast exam before you can schedule them for mammogram. So you can't simply outreach to women and say, 'Here's your mammogram date."” that it's not always the primary care provider feeling responsible, it's the whole teamlet..."

\section{Outer Setting Domain}

Patient Characteristics. Patient characteristics were mentioned in 13 interviews as a barrier to increasing mammography rates, and included factors such as patient fear, financial and time burdens, limited knowledge of the benefits of screening, and cultural barriers. As one interviewee noted, "Again, culturally, a lot of our Southeast Asian patients are not comfortable at all, and if they have newly arrived, they most definitely have not acclimated to Western medicine. They don't even have a word for 'radiology' in [Khmer]."
External Organizations. External organizations were more often perceived as barriers than as facilitators. The majority of comments pertained specifically to receipt of accurate data from hospital systems that perform mammograms on patients external to the informant's institution.

\section{CHALLENGES AND FUTURE PLANS}

Overall, interviewees were more positive in discussing their interventions and more critical of factors in the inner and outer settings. This may be because quality improvement leaders are able to select the activities in which to engage, but both the inner and outer settings have significant systemic constraints, 
such as technology availability, access to mammography services (inner setting), and payment models (outer setting) that affect the execution of these interventions and thus screening rates.

Contextual factors in the inner setting such as EHRs offer an opportunity to increase mammography screening rates, and have proved useful in measuring screening rates in other community settings, ${ }^{28}$ yet they were not fully implemented in many of the sites participating in the DSRIP program. The mixed perceptions of EHRs in our data suggest that there may be a threshold of functionality and familiarity before which health IT inhibits performance improvement and after which it enables improvement. Our findings are consistent with previous work that has found that more established EHR systems with refined functionalities offer greater benefits. ${ }^{29,30}$ Similarly, studies have shown the overall positive effects of health IT on quality of and access to care, ${ }^{29,31}$ which often come after initial reduced productivity and the creation of novel problems. ${ }^{29,32}$

Participating in performance improvement programs necessitates the collection and dissemination of data to measure change and, increasingly, to report to incentive programs. Our results are consistent with other studies examining performance improvement that have also noted the importance of timely data, ${ }^{33}$ specifically in the safety net. ${ }^{34,35}$

The adapted version of the CFIR was helpful in assessing a range of interventions directed at a single performance metric, happening simultaneously in a large number of distinct safety-net health systems. Previous studies have adapted the CFIR in similarly unique ways, ${ }^{36-38}$ but to our knowledge, few studies, if any, have used the CFIR with study-specific contextual factors for analysis of performance improvement in the safety net. The contextual factors are useful because they are more specific than the CFIR constructs, yet are largely universal in the safety net setting. In this way, safety net institutions considering innovating could assess the state of these contextual factors prior to implementation in order to help anticipate barriers. Most importantly, this work adds to the growing body of research that suggests the importance of context in performance improvement, and particularly the importance of established, integrated health IT.

Because these interviews were semi-structured and theorydriven, they may not represent a comprehensive discussion of screening practices. The interviews took place in safety-net health systems and thus may not be generalizable to other types of health systems. Moreover, we relied on staff perspectives; ethnography or other direct observation would add to the understanding of this improvement initiative. We view this theory-driven analysis of improvement efforts as a step forward in characterizing and ultimately closing the gap between evidence and practice.

\section{TEACHING COMMENTARY}

By Joseph Conigliaro, MD, MPH

\section{Synopsis of the Case:}

The state of California's Delivery System Incentive Program (DSRIP) is a pay-for-performance Medicaid waiver initiative. DSRIP plans are required to measure and report process and outcome measures. The California DSRIP went beyond the basic DSRIP requirements, and implemented a process improvement program to increase mammography screening rates in eligible women on Medicaid, who historically are less likely to receive a mammogram than wealthier insured patients, as part of the Public Healthcare Evidence Network and Innovation eXchange (PHoENIX) collaborative. The authors of this study report the implementation of this initiative using the Consolidated Framework for Implementation Research (CFIR) to evaluate the barriers and facilitators encountered during efforts to increase mammography rates in the target population. This case offers several opportunities to discuss core concepts in implementation science. In this commentary, I will focus on the role of theoretical frameworks.

\section{The role of theoretical frameworks}

The use of a theoretical framework is an important means of organizing many variables that can affect the success or failure of an implementation strategy. Theoretical models can be used not only to inform the implementation of the intervention, but also as a guide to its evaluation.

Those of us who conduct health services research have always been taught that the use of theoretical frameworks are essential, especially if one is to understand whether and how an intervention was successful. The same is true for implementation "in the field." Unfortunately, compared to evaluative research, the use of these frameworks to guide the development and analysis of implementation efforts is lacking. Davies et al. reviewed guideline implementation studies from 1968 to 1996 and found that only 53 of 235 studies (22.5\%) were judged to have employed theories, including 14 studies that explicitly used a theory. ${ }^{39}$

In this report of a mammography screening implementation in California Medicaid patients, we see how theoretical frameworks can be used to assess the success of the implementation effort. The authors used the CFIR, which utilizes features of several theories and provides a systematic approach to evaluating barriers and facilitators of an intervention. CFIR comprises five major domains: intervention characteristics, outer setting, inner setting, characteristics of the individuals involved, and the process of implementation. Within these domains are specific constructs. Constructs are explicitly defined and can be used as implementation and evaluation criteria to raise awareness of possible influential factors, facilitate the analysis of key processes and outcomes, and help organize findings of an implementation activity to explain the outcomes 
(i.e., to understand what worked where and why). ${ }^{16}$ The five major CFIR domains have 39 underlying constructs and subconstructs that can potentially influence efforts to change practice. $^{16}$

Specific constructs related to the intervention characteristics domain include the strength and quality of the evidence for the intervention. The constructs for the outer setting domain relate to those elements external to the healthcare setting such as patient needs and characteristics, as well as the healthcare resources available. The inner setting domain constructs relate to environment of care, such as culture, and leadership engagement. Constructs for the individual characteristics domain incorporate knowledge and self-efficacy. Finally, the constructs related to the process domain include planning, evaluation, and reflection.

The article by Clarity et al. offers a good example of how to use a theoretical model in program evaluation, and then how to organize the study results in the context of that theoretical framework. The authors obtained information on barriers and facilitators from key informants via semi-structured interviews, and used CFIR to interpret their data. The CFIR model allowed the content from all the interviews to be grouped under specific domains based on individual constructs. Even so, the CFIR model's 39 constructs did not completely explain all the qualitative data from those interviews, and the authors resorted to developing their own "contextual factors" to enhance the explanatory model that derived constructs from three of the five domains. Only 14 "contextual factors" within three of the domains best described the coded content from the qualitative analysis. These domains were process, inner setting, and outer setting. These three domains provided the framework within which to categorize important themes and to structure the discussion of the analysis. The authors exclude domains based on implementation design and the results of the analysis. For example, intervention characteristics were excluded because the interventions were not standardized across sites. Since CFIR was not used to inform the design of the implementation, and hence a standard intervention was not part of the implementation, interpreting this domain would have been difficult. Individual characteristics (attributes of individuals within the organization) were also excluded in the final analysis, as they did not emerge as recurring themes from the analysis of the interviews.

The article highlights the fact that even well thought-out and robust frameworks can fall short of explaining all actual data. In this example, the interventions implemented were not standardized across sites, so the specific domain related to the intervention was not interpretable.
Theoretical frameworks are useful not only for evaluating success or failure in implementing an intervention, but they can also be used to inform the design of the intervention itself. In this case, the domain of outer setting helped the investigators anticipate certain barriers in the design of their program. Factors that are representative of the outer setting domain include patient characteristics, needs, and available resources. In the presented case, patient characteristics were of particular relevance. The targeted population comprised predominantly Southeast Asian women, many of whom were newly arrived in this country. This was important both in planning the implementation and in reporting the results, in that the impact of any intervention on a specific group must be both measurable and impactful. Women of lower socioeconomic status and those who are uninsured are less likely than insured women to receive a mammogram, and therefore are more often diagnosed with later-stage breast cancer. Their unique patient characteristics were viewed as a barrier. Examples of patient characteristics in this report include the group's cultural characteristics, such as knowledge of breast cancer and its detection, language barriers and the ability of staff and provider to adequately describe the need for and importance of screening, and fear of western medicine. In addition to cultural characteristics, financial and time burdens were described as affecting mammography rates.

The adaption of CFIR by Clarity et al. in their "safety net" example can inform planners and policymakers when implementing interventions in similar settings, yet may not be appropriate in other settings. Efforts to understand key stakeholders prior to implementation using a theoretical framework can help anticipate factors regarding the patients, providers, environment processes, and resources available that will enhance or undermine a given effort. The choice of population plays an important role in the development of the intervention and the analysis of its success or failure. How populations are motivated and are able to seek preventive services is very much related to cultural and socioeconomic drivers. In addition, the specific manifestations of the targeted disease process can vary by population in a biological way. Finally, how populations are perceived by healthcare providers and the biases they encounter within the healthcare setting has an important influence on the success of targeted interventions.

In this case, the CFIR framework provides a practical - albeit insufficient - structure for approaching complex interventions in the real world. A lesson to be learned here is that there are limitations to using a theoretical framework in the analysis but not the development of an implementation effort. Could an understanding of the excluded domains a priori have contributed to a more robust implementation effort? If researchers and policymakers involved in the design 
and assessment of interventions are to see their efforts succeed, they will need to collaborate in the implementation planning stages and in adapting these models to particular situations and populations.

Corresponding Author: Urmimala Sarkar, MD, MPH; Center for Vulnerable PopulationsUniversity of California San Francisco, San Francisco, CA, USA (e-mail: urmimala.sarkar@uscf.edu).

\section{Compliance with Ethical Standards:}

Conflict of Interest: The authors declare that they have no conflict of interest.

\section{REFERENCES}

1. The Delivery System Reform Incentive Program: Transforming Care Across Public Hospital Systems. Oakland, CA: California Association of Public Hospitals and Health Systems. 2011.

2. Hsia J, Kemper E, Kiefe C, et al. The importance of health insurance as a determinant of cancer screening: evidence from the Women's Health Initiative. Prev Med. 2000;31(3):261-270.

3. Coburn N, Fulton J, Pearlman DN, Law C, DiPaolo B, Cady B. Treatment variation by insurance status for breast cancer patients. Breast J. 2008; 14(2):128-134.

4. Halpern MT, Bian J, Ward EM, Schrag NM, Chen AY. Insurance status and stage of cancer at diagnosis among women with breast cancer. Cancer. 2007;110(2):403-411.

5. Fayanju OM, Jeffe DB, Elmore L, Ksiazek DN, Margenthaler JA. Breast cancer patients' experiences within and outside the safety net. J Surg Res. 2014;190(1): 126-133.

6. Yu XQ Socioeconomic disparities in breast cancer survival: relation to stage at diagnosis, treatment and race. BMC Cancer. 2009;9:364.

7. Lobb R, Ayanian JZ, Allen JD, Emmons KM. Stage of breast cancer at diagnosis among low-income women with access to mammography. Cancer. 2010;116(23):5487-5496.

8. Byers TE, Wolf HJ, Bauer KR, et al. The impact of socioeconomic status on survival after cancer in the United States : findings from the National Program of Cancer Registries Patterns of Care Study. Cancer. 2008;113(3):582-591.

9. Taplin SH, Barlow W, Urban N, et al. Stage, age, comorbidity, and direct costs of colon, prostate, and breast cancer care. J Natl Cancer Inst. 1995;87(6):417-426.

10. Ayanian JZ, Kohler BA, Abe T, Epstein AM. The relation between health insurance coverage and clinical outcomes among women with breast cancer. N Engl J Med. 1993;329(5):326-331.

11. Schootman M, Jeffe DB, Lian M, Gillanders WE, Aft $\mathbf{R}$. The role of poverty rate and racial distribution in the geographic clustering of breast cancer survival among older women: a geographic and multilevel analysis. Am J Epidemiol. 2009; 169(5):554-561

12. Shi R, Mills G, McLarty J, Burton G, Shi Z, Glass J. Commercial insurance triples chances of breast cancer survival in a public hospital. Breast J. 2013; 19(6):664-667.

13. Niu X, Roche LM, Pawlish KS, Henry KA. Cancer survival disparities by health insurance status. Cancer Med. 2013;2(3):403-411.

14. The Safety Net Institute. CAPH/SNI Partnership with UCSF - Launches PHoENIX. [Web page]. 2015; http://safetynetinstitute.org/2013/11/07/ caphsni-partnership-with-ucsf-launches-phoenix/. Accessed June 17, 2015.

15. Fogarty International Center. Frequently Asked Questions about Implementation Science. 2013; http://www.fic.nih.gov/News/Events/implementation-science/Pages/faqs.aspx. Accessed November 5, 2015.

16. Damschroder LJ, Aron DC, Keith RE, Kirsh SR, Alexander JA, Lowery JC Fostering implementation of health services research findings into practice: a consolidated framework for advancing implementation science. Implement Sci. 2009;4:50. doi:10.1186/1748-5908-4-50.

17. National Committee for Quality Assurance. HEDIS \& Performance Measurement. 2015; http://www.ncqa.org/HEDISQualityMeasurement. aspx. Accessed March 25, 2015.
18. CFIR Research Team. The Consolidated Framework for Implementation Research Guide. http://cfirguide.org/. Accessed May 27, 2015.

19. Rycroft-Malone J. The PARIHS framework-a framework for guiding the implementation of evidence-based practice. J Nurs Care Qual. 2004;19(4):297-304

20. Hsieh HF, Shannon SE. Three approaches to qualitative content analysis. Qual Health Res. 2005;15(9):1277-1288.

21. Crabtree BF, Miller WL. Doing Qualitative Research. Thousand Oaks: Sage Publications; 1999.

22. Mandelblatt JS, Yabroff KR. Effectiveness of interventions designed to increase mammography use: a meta-analysis of provider-targeted strategies. Cancer Epidemiol Biomarkers Prev. 1999;8(9):759-767.

23. Dolan NC, McDermott MM, Morrow M, Venta L, Martin GJ. Impact of same-day screening mammography availability: results of a controlled clinical trial. Arch Intern Med. 1999;159(4):393-398.

24. Davis NA, Lewis MJ, Rimer BK, Harvey CM, Koplan JP. Evaluation of a phone intervention to promote mammography in a managed care plan. Am J Health Promotion. 1997;11(4):247-249.

25. Bodiya A, Vorias D, Dickson HA. Does telephone contact with a physician's office staff improve mammogram screening rates? Fam Med. 1999;31(5):324-326.

26. Lantz PM, Stencil D, Lippert MT, Beversdorf S, Jaros L, Remington PL. Breast and cervical cancer screening in a low-income managed care sample: the efficacy of physician letters and phone calls. Am J Public Health. 1995;85(6):834-836.

27. Agency for Healthcare Research and Quality. Defining the PCMH. The Patient Centered Medical Home [Webpage]. 2015; http://pcmh.ahrq.gov/ page/defining-pcmh. Accessed May 27, 2015.

28. Baker DW, Liss DT, Alperovitz-Bichell $\mathbf{K}$, et al. Colorectal cancer screening rates at community health centers that use electronic health records: a cross sectional study. J Health Care Poor Underserved. 2015;26(2):377-390.

29. McAlearney AS, Robbins J, Hirsch A, Jorina M, Harrop JP. Perceived efficiency impacts following electronic health record implementation: an exploratory study of an urban community health center network. Int $J$ Med Inform. 2010;79(12):807-816.

30. DesRoches CM, Campbell EG, Rao SR, et al. Electronic health records in ambulatory care-a national survey of physicians. N Engl $\mathrm{J}$ Med. 2008;359(1):50-60.

31. Buntin MB, Burke MF, Hoaglin MC, Blumenthal D. The benefits of health information technology: a review of the recent literature shows predominantly positive results. Health Aff (Millwood). 2011;30(3):464-471.

32. Scott JT, Rundall TG, Vogt TM, Hsu J. Kaiser Permanente's experience of implementing an electronic medical record: a qualitative study. BMJ. 2005;331(7528):1313-1316.

33. Wagner EH, Austin BT, Davis C, Hindmarsh M, Schaefer J, Bonomi A. Improving chronic illness care: translating evidence into action. Health Aff (Millwood). 2001;20(6):64-78.

34. Lyles CR, Aulakh V, Jameson W, Schillinger D, Yee H, Sarkar U. Innovation and Transformation in California's Safety Net Health Care Settings: An Inside Perspective. Am J Med Qual. 29 2013.

35. Pourat N, Davis AC, Salce E, Hilberman D, Roby DH, Kominski GF. In ten California counties, notable progress in system integration within the safety net, although challenges remain. Health Aff (Millwood). 2012;31(8):1717-1727.

36. Cunningham P, Felland L, Stark L. Safety-net providers in some US communities have increasingly embraced coordinated care models. Health Aff (Millwood). 2012;31(8):1698-1707.

37. Robins LS, Jackson JE, Green BB, Korngiebel D, Force RW, Baldwin LM. Barriers and facilitators to evidence-based blood pressure control in community practice. J Am Board Fam Med. 2013;26(5):539-557.

38. Richardson JE, Abramson EL, Pfoh ER, Kaushal R. Bridging informatics and implementation science: evaluating a framework to assess electronic health record implementations in community settings. AMIA Annu Symp Proc. 2012;2012:770-778.

39. Davies P, Walker AE, Grimshaw JM. A systematic review of the use of theory in the design of guideline dissemination and implementation strategies and interpretation of the results of rigorous evaluations. Implement Sci. 2010;5:14. 


\section{APPENDIX 1}

Table 3 Characterization of Interviewees

\begin{tabular}{|c|c|c|c|}
\hline $\begin{array}{l}\text { Health } \\
\text { system }\end{array}$ & Interviewee(s) title(s) & $\begin{array}{l}\text { Number of } \\
\text { interviewees }\end{array}$ & $\begin{array}{l}\text { Clinician type } \\
\text { represented } \\
\text { (if applicable) }\end{array}$ \\
\hline 1 & Chief Medical Officer/Medical Director & 1 & MD \\
\hline 2 & Chief Medical Officer and Director of Quality Services & 2 & DO; non-clinician \\
\hline 3 & MD, Clinical Associate Professor of Medicine, Mammography Champion & 1 & MD \\
\hline 4 & Medical Director, Quality Improvement & 1 & MD \\
\hline 5 & Medical Director of Quality (1) and Chief Medical Informatics Officer (1) & 2 & MD \\
\hline 6 & Chief Medical Officer (1) and Chair Department of Primary Care (1) & 2 & MD \\
\hline 7 & Medical Home Manager (1) and Medical Director, Ambulatory Services (1) & 2 & $\begin{array}{l}\mathrm{RD}, \mathrm{MPH} ; \text { non- } \\
\text { clinician }\end{array}$ \\
\hline 8 & $\begin{array}{l}\text { Deputy Director, Ambulatory Administrator (1) and Ambulatory Care Medical } \\
\text { Director (1) }\end{array}$ & 2 & MD; non-clinician \\
\hline 9 & Chief Information Officer (1) and DSRIP Project Director (1) & 2 & Non-clinician (2) \\
\hline 10 & Senior Deputy Director, Ambulatory Care Services & 1 & Non-clinician \\
\hline 11 & $\begin{array}{l}\text { Chief, Division of Primary Care (1) and Director of Primary Care and } \\
\text { Community Health Services (1) }\end{array}$ & 2 & MD; non-clinician \\
\hline 12 & Executive Medical Director, Primary Care & 1 & MD \\
\hline 13 & Medical Director, PCMH & 1 & MD \\
\hline 14 & MD, Mammography Champion - Associate Medical Director & 1 & MD \\
\hline $15-16^{*}$ & Chief Medical Officer & 1 & MD \\
\hline $17-20^{*}$ & $\begin{array}{l}\text { MD, Mammography Champion - Director of Women's Health Programs and } \\
\text { Innovation }\end{array}$ & 1 & MD \\
\hline \multicolumn{2}{|c|}{ Total systems represented } & $\begin{array}{l}\text { Total interviewees } \\
23\end{array}$ & $\begin{array}{l}\text { Total interviews } \\
16\end{array}$ \\
\hline
\end{tabular}

*These distinct systems jointly report performance measures to the state health department as part of their consolidated DSRIP plans

\section{APPENDIX 2 - SEMI-STRUCTURED INTERVIEW GUIDE Questions to assess mammography practices across California's public hospital systems}

1. Can you describe for me the background of how your system conducts mammography outreach to patients and follows up with results?

a. Walk me through what it looks like when it is working at its best, what each of the steps are.

b. Now describe what points of "pain" you have encountered-maybe an example?

c. Now let's discuss some of the strategies you use at different steps of the process.

2. How do you identify who in your system needs mammography screening?

a. Are some women doing well because they are getting a mammogram every year?

b. Probe: Catchment area based on geography (i.e., SF city \& county) or recent patients at the system (e.g., primary care or specialty care visits in the past 2 years)?

3. What are the strategies and practices used to reach women to get them screened?

a. Probe: In-person reminders at visits, reminder letters, follow-up phone calls, panel management/registries? b. Probe: Different tactics at each ambulatory care clinic? Single person assigned responsibility for management (e.g., Medical Assistant's panel)?

c. Probe: Time/cost of these programs (e.g., 0.2 FTE of a nurse care manager)?

d. Are these systems applied or applicable to other screening/ population management topics (such as colon cancer screening or vaccination)>

4. How do you track the results of these practices?

a. Probe: Electronic record systems capturing mammography visits, sampling of mammography visits to estimate rates?

b. Probe: How do your current data systems facilitate or inhibit tracking?

5. Are there data to know what strategies work best?

a. Probe: Certain clinics performing best, current screening rates shared and posted publicly?

6. Have your strategies and practices changed significantly in the past 2 years?

a. If yes, can you briefly describe the changes?

7. Do you know of other places in the community that eligible women from your system can be screened?

a. Are women getting mammograms that are outside of the system, for which data is not recorded? 
b. Probe: Mobile vans, health fairs, other free healthcare choices?

8. If you could do one thing differently in your system to increase rates, what would that be? And what would it take to do it?

a. How do you think you got such good uptake?

b. What do you think stands in the way to achieving higher rates?

9. What are some of the barriers/challenges to implementing effective mammography screening practices?
10. How can we usefully share best practices to help improve breast cancer screening?

a. What format do you prefer (e.g., PPT, webinar)?

11. Are there any challenges/barriers to patients getting screened?

a. Are there cultural issues?

b. Lack of understanding?

12. Who in your organization should we share our findings with?

a. Is there a group tasked with this project?

b. Can you send us their contact information? 